\title{
Space science celebrated on Sputnik's thirtieth birthday
}

Moscow

THE international space research community last week celebrated the 30th anniversary of the first Soviet Sputnik, launched on 4 October 1957, with a symposium on the future of space research destined, from the outset, to turn into a gigantic party. By the end, most participants were convinced that the next step forward is an international collaboration for the exploration of Mars, but official government cheque-books were conspicuous by their absence.

Last week's event was the brain-child of Academician Roal Z. Sagdeev, the plasma physicist turned manager of the Soviet civil space research programme, and now director of the Space Research Institute of the Soviet Academy of Sciences. Sagdeev was described on Sunday by a member of the US delegation as the man whose enthusiasm for international collaboration now promises to set its stamp on the pattern of research in the United States and elsewhere.

More than 250 people from outside the Soviet Union, together with an equal number of Soviet scientists, were assembled for the celebration. A genial Soviet cosmonaut explained that the gathering included 41 astronauts and cosmonauts (the Soviet equivalent), the largest gathering of such people "in the history of the business".

The tenor of the proceedings was remarkable for its amity. Soviet speakers went out of their way to congratulate the United States for its achievements during the past 30 years, the "brilliant success" of the Apollo programme included. One Soviet speaker even drew attention to the hazards of the space business, emphasizing the difficulties of running manned spaceflights on a tight schedule.

The formal proceedings finished with a conversation between two orbiting members of the Soviet squad, three ground-based astronauts (one from the United States), Sagdeev, Academician G.I. Marchuk, president of the Soviet Academy and Mrs Carl Sagan (whose husband was taken ill after delivering an upbeat address to the symposium). The

\section{Japanese finance: correction}

AN article in Nature of 17 September (329, $188 ; 1987)$ stated in regard to the reorganization of the Astronomical Observatory of Tokyo University into a national research institute that "funds for reorganization were requested this fiscal year but were turned down by the Ministry of Finance". In fact, a small budget for "preparation for reorganization" was allotted in this fiscal year. conversation was a telling reminder of the difficulty of avoiding banality on these occasions.

The meeting's formal decisions were few, but none the less interesting on that account. There is to be a study of the potential usefulness of satellites as a means of relaying data of urgent significance to developing countries - epidemiological data about AIDS (acquired immune deficiency syndrome) and information about natural disasters, for example. Two groups, based in Boston and Moscow, will try to devise a workable scheme by the end of the year.

The United States plans to hold another conference on future directions in space research in the middle of next year. The $\mathrm{V}$ International Association of Space Artists

\section{IMAGE UNAVAILABLE FOR COPYRIGHT REASONS}

Sputnik I - the first official photograph of the 30-year-old Earth satellite released from Moscow on 9 October 1957

(whose members exhibited their largely representational works at the celebrations) will arrange a travelling exhibition in the months ahead. The conference adopted a resolution (read by Ms Susan Einsenhower, whose grandfather was US president at the time of the first Sputnik) urging collaboration in the peaceful uses of outer space, particularly during the international space year planned for 1992.

Enthusiasm for the exploration of Mars has been largely stimulated by Soviet plans for the years ahead. The rocket for the flight to the martian satellite Phobos will be launched next year, but Soviet participants at last week's conference gave a detailed account of the missions they plan to send to Mars beginning in 1992. The plan is that a series of rocket flights should recover information about the surface of the planet by remote sensing and that there should be a series of landings on the surface of the planet by various roving instruments with the intention that samples should eventually be recovered. The most intriguing candidate design for the surface vehicle is one consisting of a gas balloon and a hot-air balloon linked together so as to drift above the surface during the martian daylight. The design is being developed jointly by Soviet and French groups.

The symposium also provided a valuable summary of some recent astrophysical results. The discovery of a curious gravitational lens in which a pair of images is superimposed on a diffuse ring of radio luminosity was reported from the Very Large Array telescope in the United States, and various luminaries such as $\mathrm{Ya}$. B. Zeldovich and Andrei Sakharov provided a perceptive account of the state of cosmology. The principle seems to be that ambitions should be unconstrained.

John Maddox

\section{IVF rules under pressure to change}

\section{London}

Pressure for rapid legislation on in vitro fertilization and embryo research is mounting in Britain following the flouting by a London clinic of voluntary guidelines. The privately funded Humana Hospital Wellington ignored guidelines imposed by the Voluntary Licensing Authority (VLA) by transferring more than four eggs at a time. The hospital has been struck off the VLA's list of approved clinics but remains free to continue to practise because the VLA has no statutory powers.

The VLA announced the new guidelines in May (see Nature 327,$92 ; 1987$ ) and gave clinics until September to bring their practices into line. The Wellington was the only one of 30 in vitro fertilization clinics in Britain that refused to provide the necessary assurances.

There are indications that the VLA might be prepared to reconsider one of its new guidelines (also announced in May) forbidding the donation of eggs by the relatives of infertile patients, in line with its principle that the anonymity of the donor is paramount in the interest of the child. The VLA now acknowledges that some clinics feel that this rule should not be inflexible. The question will be raised at the clinics' annual meeting next month.

The VLA was set up two years ago by the Royal College of Obstretricians and Gynaecologists and the Medical Research Council following the completion of the Warnock report, commissioned by the government, on human fertilization and embryology, which recommended a statutory licensing authority. A long-awaited government white paper (policy statement), based on the Warnock report, is due in late November. Simon Hadlington 